\title{
Correspondence
}

\section{One psychiatric hospital?}

\section{Dear Sir}

Dr Dey (August 1980) draws attention to the treatment of the mentally handicapped person who is also mentally ill. This, however, is only part of a wider concern for the psychiatric treatment and management of the mentally handicapped and their families, which is particularly complicated by the problem of their residual accommodation when, or in many cases if, they are satisfactorily treated.

Dr Dey's proposal of psychiatric comprehensives for all the mentally disorded runs counter to the post-war trend for the development of more selective units, especially in general hospitals and academic departments, whose policy has, ipso facto, been dicated by a fear of 'silting up'. In the face of this the larger traditional hospitals have understandably also become more sensitive about being involved with the mentally handicapped-a situation not helped by the publicity surrounding some seemingly rehearsed Inquiriesand the psychiatric care of the handicapped is consequently in danger of becoming a lost cause. This is reflected, for example, in the paucity of papers on mental handicap published in the Journal in the past 3-4 years; it is perhaps not without significance that this coincides with the lifetime of the National Development Group.

But why does Dr Dey allege that 'nurses (of the mentally handicapped) are not trained to deal with mentally ill patients'? If this is so, what in fact comprises a sizeable part of their specialized training? It may be that, under threat from the Jay Committee, they have defended themselves in depth by becoming more involved in, for example, social work or further education-a position that seems to be reflected in their present training syllabus. Now, however, that this threat has receded, could they not again become more concerned with the realities to which Dr Dey has drawn attention, so that hospitals for the mentally handicapped could themselves respond to the psychiatric challenge?

Claypenny Hospital

T. L. Pilkington York, Y06 3PR

DeAR SiR,

\section{'Trakison des cleres'}

I suspect that Professor Batchelor (Bulletin, September, 1980, p. 143) has overlooked a couple of points about the use of the expression 'Bins' to refer to mental hospitals.

The first, and very much the lesser, is that this usage is very often merely an example of 'professional slang', something which the medical profession uses no less widely than most other professions, and an almost universal feature of which is a depreciatory atmosphere.

The rather more important point concerns the nature of the power of pejorative and stigmatic expressions generally. Attempts to deal with the problems of expressions which have become unpleasant by connotation (from a plethora of examples one might select 'fits', 'cancer', or even 'rat catcher' and 'dustman') by avoiding their use, have shown themselves to be vain: the unpleasant connotations merely attach themselves to whatever expression is chosen to replace them. On the other hand, attempts to deal with such problem expressions by deliberate and unemotional over-use, with the object of devaluing their power, can be seen to have considerable if gradual success. (As a more general example of this, the increasingly widespread use of four-letter words in broadcasting, the Press and literature has very considerably reduced their impact in individual situations.)

It is worth remembering that neither the expression 'the Bin' nor the stigma attached to institutions, started life in the practices of psychiatrists.

St Andrew's Hospital,

Peter Eames Northampton, NNI SDG.

\section{DeAR Sir,}

\section{Comanunity psychiatric nursing}

I read with interest the discussion document on Community Psychiatric Nursing (Bulletin, August 1980), having worked closely with CPNs in three different areas. Organization, caseload and experience vary widely, but one difficulty seems to be common to all. Not all CPNs are lucky enough to be able to relate to a single consultant team, but even for those who do so there is often a feeling of isolation from the rest of the team. This is especially marked in large catchment areas or where the base hospital is situated outside the area. Although nursing officers can provide valuable support, and there are usually good contacts with social services, obtaining psychiatric advice can often prove a tedious and lengthy task.

I believe that one solution is the service which I have developed with one group of CPNs and have just initiated with another. One session a week is devoted to a meeting with the CPNs. This is put to whatever use they feel is most appropriate-discussing general topics or specific patients; if necessary the patients attend for review. Home visits are made if the patient does not wish to attend or if it is felt that this would clarify the situation. I am also available for advice during the week and make urgent home visits, although in practice there is little which needs to be dealt with outside the 
regular weekly seasion. Notes are kept in the CPNs file and a copy of all letters go to the GP. Permission is always obtained from the GP before a home visit.

This regular commitment has proved very popular with the CPNs. Such a service would seem ideally suited to senior registrars since not only are they sufficiently experienced to provide the necessary support for the CPNs whilst having hospital service commitments which are not unduly heavy, but they also stand to gain valuable experience in community and team work.

P. C. Thomas

Shenley Hospital.

Herts.

\section{Doctors and counsellors-collaboration or confilet?}

\section{Dear SiR}

I would like to congratulate Audrey Newsome on her excellent article 'Doctors and Counsellors-Collaboration or Conflict?' in the July Bulletin, p 102.

Working as Fellow in Community Psychiatry for the last two years, my experiences confirm most of her observations. In addition to my established role of working with the unique neighbourhood workers (housewives acting as "barefoot' social workers) in the Craigmillar district of Edinburgh, I have increasingly found myself involved in collaboration with other counsellors in the Edinburgh area, derived from many different groups. I have little doubt that it is not only feasible but highly desirable to maintain a symbiotic relationship between para-professional counsellors and hospital psychiatric services.

We need each other! Our work is not only complementary but frequently overlaps. Yet, until the ivory towers of the hospital psychiatric services are prepared to let down their defences and promote communication and shared support with the counsellors, this symbiosis cannot take place.

Some of our patients are better suited to peer-group counselling and support in a non-medical setting, and some of their clients are in need of psychiatric support, and occasionally a counsellor needs reassurance that a client is not psychiatrically ill.

By having a 'free-floating' psychiatrist, accepted both by the hospital staff and in regular familiar contact with the counselling services (including area team social workers, of course), it is possible to allow much freer interchange of patients and clients, and of ideas, training and support-to the benefit of hospital staff and counsellors, as much to the clients themselves.

Thus in one section of Edinburgh at least it has been possible to promote more community counselling support and back-up than hitherto for former psychiatric in-patients and out-patients. For the counsellors working with wife-battering and other difficult problems, there has been the opportunity for more psychiatry back-up and liaison with hospital staff.

I have not found the issue of confidentiality to be a particular problem-always seeking patients' or clients' approval before referrals are made in either direction; nor have I found GPs objecting to this shared approach to a difficult and demanding population.

Royal Edinburgh Hospital

JUDY GREENWOOD

Edinburgh

\section{Senior registrar training}

\section{DeAR SIR}

I have read with interest the review on Senior Registrar Training in General Adult Psychiatry by Robert Fieldsend of the Warneford Hospital in the August Bulletin and was glad to note the importance he attaches to the training opportunities for Senior Registrars.

When I was Head Social Worker at the Child Guidance Training Centre, where I worked with and also taught Senior Registrars, I was interested in this aspect, and now, in my capacity as Principal Consultant to a Social Services Department, I am much involved in the area of staff development for Social Workers. I therefore understand Dr Fieldsend's concern that he and other Senior Registrars should be given as many learning opportunities as possible. However, it disturbs me greatly that in this interesting article the consideration of patient needs does not get any mention. It seems to me regrettable that the needs of the learner are stressed to such a high degree, whereas the needs of the receiver are not. My post is one that focuses on client needs. Who in the adult psychiatric setting deals with the needs of the psychiatric patient?

ILSE J. WESTHEMER
Abbey Mill House

Reading, RG1 $3 B H$ 